Revista Iberoamericana, Vol. LXXIII, Núm. 220, Julio-Septiembre 2007, 581-594

\title{
COSMOPOLITISMO ANDINO: EXPLORANDO EL LADO FEMENINO DE LIMA
}

POR

Priscilla Archibald

Roosevelt University

Como el novelista y antropólogo José María Arguedas predijera en los sesenta, la emigración andina en Lima ha producido un nuevo ritmo social en dicha ciudad. Llamada en ocasiones cultura de la chicha, los andinos de la urbe han dejado su huella en todas partes. Ya se trate de los mini=buses que abarrotan las que fueran las calles del antiguo Estado colonial, de los vendedores ambulantes que ofrecen desde patatas hasta polleras a los últimos cd's, o del hombre que intenta vender caramelos a los automovilistas detenidos por el cada vez más denso tráfico de Lima, es innegable que la cultura de la chicha ha transformado de manera drástica esta ciudad colonial tan tradicional. El término chicha se refiere concretamente a un nuevo tipo de música urbana producido por los residentes más recientes de Lima. Representa el cruce de la cultura andina con la tecnología, tanto en términos de composición como de distribución. La chicha no sólo se escucha en los barrios populares donde tuvo su origen sino que ha penetrado en sectores de las clases media y alta, llegando a ser la música más popular y de mayor éxito comercial del Perú_(Rowe y Schelling 59). En ocasiones se habla de ella más como un modo de vida que como una forma artística concreta. De esta manera, se integra profundamente en los intercambios étnicos y raciales de la Lima moderna, intercambios captados con habilidad en el título del estudio de Guillermo Nugent El laberinto de la choledad. ${ }^{1}$ Este título juega con la alusión al clásico de Octavio Paz, El laberinto de la soledad, rompiendo de este modo con la posición privilegiada de la cultura occidentalizada, del mismo modo que la chicha resignifica el anteriormente tan tradicional vocabulario cultural de Lima. William Rowe y Vivian Schelling retratan vivamente este cruce híbrido entre tradición y modernidad que caracteriza a la chicha:

[Chicha is] an Andean melodic style with tropical and electric guitar as lead instrument. The lyrics refer not to collective experience but to individual lives in a context of urban dispersal where the traditional Andean universe has become fragmented ... Chicha developed out of the wayno or waynu, an originally pre-Columbian musical form, and it is difficult to decide whether it represents an Andeanization of international styles or an

\footnotetext{
${ }^{1}$ Cholo es el término coloquial usado para el mestizo. Designa a la persona urbanizada de origen
} indígena. 
internationalization of the Andean, whether it is an impoverished dilution of the elements it mixes or on the contrary an exciting crossing of frontiers and a matrix for new musical departures. (59)

([La chicha es] un estilo melódico andino con ritmo tropical y guitarra eléctrica como instrumento principal. Las letras refieren no ya la experiencia colectiva sino las vidas de individuos en un contexto de dispersión urbana donde el tradicional universo andino se ha visto fragmentado... La chicha evolucionó del wayno o waynu, una forma musical precolombina en su origen, y resulta difícil decidir si representa una andinización de estilos internacionales o una internacionalización del andino, si es una solución empobrecedora de los elementos que mezcla o, por el contrario, se trata de un emocionante cruce de fronteras y matriz de nuevos rumbos musicales.)

Comienzo con esta referencia a la chicha o cultura de la chicha, primero, porque esta se ha convertido prácticamente en sinónimo de la vida andina en la ciudad; y, segundo, porque dramatiza de modo inequívoco el carácter profundamente ambivalente de la modernidad alternativa que la Lima contemporánea supone.

Como centro del régimen colonial en Sudamérica, las costumbres virreinales de Lima han sido siempre fuente de orgullo para los habitantes de la ciudad. Pocos ejemplos mejores podríamos encontrar de lo que Ángel Rama llamó la “ciudad letrada” que las agudas descripciones que Ricardo Palma hiciera de Lima en el siglo XIx. Las últimas décadas, no obstante, han impugnado esta autodefinición criolla. En 1940, la población era aproximadamente de quinientos mil habitantes. Hoy en día, la cifra ha alcanzado los siete millones, y es con toda certeza la emigración rural la fuente principal de dicho crecimiento (Burt y Espejo 20). Con el ochenta por ciento de sus barrios albergando a los sectores populares, Lima ha tomado un carácter andino distintivo (Matos Mar 71). Si la emigración andina ha supuesto pobreza, penurias y desarraigo, los andinos de la ciudad han mostrado también una notable capacidad de adaptación y apropiación. Los criollos, en tanto, han probado ser mucho menos adaptables, parapetándose en bolsas culturales propias cada vez más reducidas. La sensación de estos criollos de hallarse en el centro de una cultura que se extendió hacia fuera, dominando aquello que le era adverso, ha dado un giro repentino. Dado este clima de desarticulación cultural y social criolla, uno se pregunta si su comprensión del término andino pachacuti -el cual hace referencia a una transformación cataclísmica global- será más inmediata. Se trata, en última instancia, de una crisis hegemónica.

Vivir los orígenes heterogéneos del colonialismo no ha sido fácil para las élites de Lima. Su desarrollo de lo que Mary Louise Pratt llama "the arts of the contact zone" ("las artes de la zona de contacto”) ha sido tardío. “¡Nos están quitando el país!”, exclamó un periodista con candidez (Bueno 262). En el cuento de Jaime Bayly “Extrañando a Diego”, el narrador señala con prosaísmo cómo Lima, para una clase alta moralmente sospechosa, ha quedado confinada a unas cuantas cuadras. El retrato altamente distópico que de la Lima moderna hace el novelista Mario Vargas Llosa en su Historia de Mayta, proporciona una sensación inolvidable de la desesperación criolla. En respuesta a este desorden interno, 
simbolizado principalmente por la acumulación de basuras y la totalmente impropia presencia andina en la ciudad, así como por la inminente pérdida de territorio que plantea la amenaza de invasión por parte de las superpotencias mundiales, la memoria proporciona el único refugio. El narrador sueña con revivir la Lima de los años cincuenta, momento inmediatamente anterior a que la afluencia campesina se dejase sentir en la ciudad. En este caso es el privilegio criollo el que resulta curiosamente provincial e impotente.

No sólo han llegado a cuestionarse las duraderas representaciones criollas de la ciudad sino que la no menos importante emigración andina ha requerido una reelaboración del modelo tradicionalista. El romance descolonizador guionizado por los indigenistas durante las primeras décadas del siglo xx establecía a los indígenas como los verdaderos nacionales. Su cultura, presentada como inmutable y pura, era reconocida por estos escritores como el patrimonio esencial del Perú. El tradicionalismo de este modelo se opone a lo moderno, y cualquier contacto con Occidente se concibe como una pérdida irreversible. Si este modelo tradicionalista fue una de las armas más importantes en las luchas por la descolonización, también fue, en un sentido más amplio, resultado de la dominación política y económica occidental, definiendo y demarcando aquellas regiones que entraban en la visión de Occidente. En la última década se han sucedido innumerables críticas del tradicionalismo. Los antropólogos en particular han desmantelado con rigor la noción del sujeto tradicional o primitivo que fuera premisa de su disciplina. Aun así, en el Perú, ninguna crítica ha sido tan completa como el ejemplo de los propios andinos de la urbe.

El modelo tradicionalista aún era claramente operativo en los años sesenta, cuando los sociólogos comenzaron a lamentarse por los “cinturones de miseria” que rodeaban Lima. Según estos, la relación de los andinos con la ciudad era de desajuste y se caracterizaba por la nostalgia melancólica de su lugar de origen. Veinticinco años después, el economista Hernando de Soto en su libro El otro sendero, que ha sido un éxito de ventas, ofrece una imagen de la adaptación andina a la ciudad muy diferente. De Soto narra una historia heroica, caracterizada por una incesante actividad e ingenuidad por parte de los andinos. Centrándose en la vivienda, el comercio y el transporte, documenta la construcción por parte de los andinos del sector informal, un sistema paralelo al Perú oficial y que crece en proporción exacta a la incapacidad del Estado para satisfacer las necesidades más básicas de sus gentes. En vez de sufrir la parálisis cultural y la desintegración que sociólogos y críticos literarios detectaran en los años sesenta, los andinos de la urbe constituyen para De Soto los residentes esenciales y representan la expresión de un individualismo incontenible, un ejemplo puro del espíritu empresarial y la incontrovertible evidencia de que el equivocado historial intervencionista del Estado en el Perú debería reemplazarse con una economía de libre mercado. Este retrato del sector informal ha convertido a De Soto en una suerte de celebridad tanto en América del Norte como del Sur, granjeándole un perfil destacado en la política peruana. Fue un miembro de confianza del círculo del novelista y candidato conservador a la presidencia Mario Vargas Llosa (quien escribió el prefacio a El otro sendero), para cambiar de bando tras la victoria de Alberto Fujimori en 1990. Si De Soto parece capturar el espíritu de la ciudad con mayor precisión que sus predecesores, sus tendencias ideológicas, por otro lado, previenen otras 
interpretaciones posibles de la vida en la ciudad. Que la tendencia empresarial sea la expresión adecuada para retratar la actividad económica que implica normalmente el mantenimiento y la reproducción familiares, en vez de la acumulación de capital y la expansión comercial, es en realidad discutible. Y, cualesquiera las implicaciones últimas del sector informal, la planificación y el espíritu de cooperación entre los andinos que celebra De Soto son, al menos en parte (y como muchos han observado), producto de relaciones sociales -reciprocidad o economía de la familia extendida por ejemplo- de naturaleza más colectiva. En lugar del proceso de aculturación que se llegó a creer consecuencia inevitable del contacto de la sociedad tradicional con Occidente, y que Martin Lienhard llama de manera tan acertada "pseudo-concepto” al ser menos una teoría social que un indicio de "etno-política”, la cultura andina parece haberse revitalizado en Lima: los andinos se hallan menos prestos a prescindir de sus tradiciones culturales hoy en día ( $L a$ voz 93). El quechua, que ha dejado de ser la lengua vergonzante cuya defunción previera tristemente José María Arguedas en los años cuarenta, puede oírse ahora por las calles de la ciudad. Y como el estudio de Martin Liehard La voz y su huella establece, el quechua puede ahora reclamar la condición de lengua escrita (144-5). La vestimenta tradicional andina, en forma de polleras y enaguas, se ve en casi todos lados, a menudo complementando variedades más occidentales, y los puestos de las esquinas traen los olores de la comida del altiplano. El huayno andino, una canción de origen precolombino, constituye igualmente un lugar común de la ciudad estos días. No obstante, e igualmente importante, Lima no es sólo la sede donde las tradiciones andinas se perpetúan sino también una reelaboración de lo que significa ser andino. La radio y la televisión están omnipresentes en los pueblos jóvenes y son los medios de comunicación hoy día el principal modo de propagación de la cultura andina. Con el mayor porcentaje de artesanos peruanos, así como los más prestigiosos de entre ellos, viviendo en Lima, está claro que los andinos han aprendido a manipular el mercado del folklore (véase García Canclini, cap. 5). Dada la hibridez racial de la cultura de la chicha, la oposición paradigmática entre “tradición” y “modernidad” que ha sido centro de la comprensión occidental de la cultura, la historia y la sociedad, ha perdido su vitalidad como concepto operativo.

NACIONALISMO: ¿AUMENTO O DISMINUCIÓN?

El modo en que la dislocación cultural andina se solapa con características que se identifican como "posmodernas" -el dominio de lo híbrido, el predominio de los medios de comunicación de masas y el consiguiente allanamiento de la distinción cualitativa entre la cultura de la clase alta y la cultura popular-parece indicar el fin del hechizo de las viejas narrativas nacionalistas cuyo énfasis en la autenticidad y la autonomía fuera tan convincente durante la primera mitad del siglo xx. Según Neil Lazarus, la identificación de procesos ligados a la globalización con la posmodernidad cultural y la consiguiente mengua del sentimiento nacionalista equivalen a un tipo de sentido común contemporáneo (47). Este se encuentra no sólo donde podría esperarse, como entre los practicantes de la filosofía y la estética posmodernas y los teóricos de lo posnacional, sino entre pensadores que en ocasiones muestran cierto escepticismo con respecto a estas tendencias culturales. Fredric Jameson, por ejemplo, señala que 
My sense is that the old and fundamental opposition, in the colonized world, between Westernizers and traditionalists, has almost completely disappeared in this new postmodern moment of capitalism. That opposition was, so to speak, a modernist one, and it no longer holds for the very simple reason that tradition in that form has everywhere been wiped out... In that sense also the opposition between the metropolis and the provinces has also disappeared, both nationally and on a global scale..._(66)

[Mi opinión es que la vieja y fundamental oposición, en el mundo colonizado, entre occidentalizadores y tradicionalistas ha desaparecido casi por completo en el nuevo momento posmoderno del capitalismo. Esa oposición era, por así decirlo, modernista, y ya no se sostiene por la simple razón de que esa forma de tradición ha sido borrada en todos lados... En ese sentido, también la oposición entre la metrópoli y las provincias ha desaparecido, tanto a escala global como nacional...]

No obstante, esta forma de sentido común contemporáneo se ve profundamente cuestionada por Lima, o al menos así lo ven los intérpretes de la ciudad. Las propuestas nacionalistas no han desaparecido. En 1984, el antropólogo José Matos Mar publicó un estudio sobre Lima y los efectos de la emigración andina que abrió el camino. Desborde popular y crisis del estado se agotó en cinco meses. Cuatro años más tarde, se habían impreso seis ediciones más. Uno no puede sino especular sobre el hecho de que esta desbordante recepción se hallara en proporción directa a la desorientación producto del cambio demográfico. Matos Mar dibuja la imagen de una lucha claramente nacionalista. Al describir la emigración andina como "la invasión de nuevas áreas” de la ciudad y "la captura del casco”, Matos Mar emplea el lenguaje de la territorialidad nacional (76). Los llamamientos regionalistas o territoriales, minados por el éxodo rural, son reubicados en el nuevo y cambiante espacio de la ciudad. Matos Mar narra la historia de la victoria andina ya que, como el título Desborde popular indica, el Perú oficial se halla literalmente dominado por lo que uno sólo puede denominar como sus elementos más auténticos.

Este libro marca una transición crucial, ya que trasciende la ortodoxia en que la presencia urbana andina se construye como, por un lado, una cuestión de pérdida cultural para los andinos, y por otro, el fracaso en conseguir la modernidad (al estilo occidental). Como sucediera con la redención nacional de De Soto, para Matos Mar ésta se encuentra en el sector informal. Sin embargo, donde De Soto confirma a su lector las implicaciones últimas de los desarrollos que describe, haciendo notar que aun cuando el inmigrante andino puede operar en la ilegalidad no es en definitiva “antisocial”, Matos Mar retrata al sector informal como una alternativa radical:

La gente se organiza espontáneamente para la solución de sus problemas de agua, alumbrado, asfaltado ... compensan el alto costo o ineficacia de los servicios médicos y de la salubridad, acudiendo en número cada vez mayor a los consultorios de curanderos y herbolarios .... Violando las normas del sector de Educación ... Rompiendo con los límites legales ... enfrentando con las ineficientes estructuras policiales ... (91)

El vocabulario que Fredric Jameson cree inaplicable a la realidad social contemporánea impregna el estudio de Matos Mar. La separación entre metrópoli y periferia se hace 
operativa de verdad cuando proclama la ilegitimidad de un Estado que "desconoce la lengua y tradición mayoritaria, mientras que se expresa en lenguajes y formas de origen extranjero" (108). No es éste un gesto aislado o atípico por parte de Matos Mar sino que se ve repetido en mucha de la literatura contemporánea sobre Lima y el Perú en general. El crítico literario Raúl Bueno, por ejemplo, hace alusión a la obra descolonizadora de la gran figura del nacionalismo cubano José Martí al escribir: "Estamos viendo que el país natural ‘vence’ al país artificial” (262). Bueno llega al punto de declarar la heterogeneidad específica de los peruanos -“celebrando nuestra (no simplemente la) diversidad”-, una estrategia retórica que mantiene el paso de la lógica cultural contemporánea al tiempo que detiene las implicaciones últimas del mundo poscolonial (23). Este ímpetu nacionalista se hace evidente en el giro generalizado hacia temas andinos que ha caracterizado a los estudiosos desde los años ochenta (véase Matos). Aquellos de tendencia conservadora retratan con frecuencia este interés por "lo andino" como "neo-indigenismo", como "romántico, pasadista, resultado del afán de huir del presente y de buscar algo de que asirse en el pasado” (Flores Galindo “El rescate...” 8). Los estudiosos contemporáneos del mundo andino, no obstante, mantienen pocas similitudes con el indigenismo esencializador de los años veinte en tanto se halla claramente compuesto por lo que se ha dado en llamar el "giro lingüístico". El interesante híbrido de posestructuralismo y andinismo del presente ha producido tremendas innovaciones en la historia, la literatura y la antropología entre otras disciplinas, y representa un intento, como Fernando Calderón dijera respecto a Bolivia, de "pensar la modernidad sin dejar de ser [peruano]". William Rowe y Vivian Schelling señalan que "of all the regional cultures of Latin America, [Andean culture] is the one which can most strongly lay claim to being an alternative civilization" (51) [de todas las culturas regionales de Latinoamérica, [la andina] es la que puede reclamar con mayor fuerza el ser una civilización alternativa”]. Este comentario sugiere el tipo de carga utópica que inspira el andinismo. Además, no sólo la fuerza de la tradición andina contribuye al sentido de alternativa y posibilidad utópica, sino que, como hace evidente el espléndido libro de Alberto Flores Galindo Buscando un Inca, ese mismo utopismo es una característica permanente de la cultura andina tras la conquista. Este es un caso a favor de la continuidad representada por el cosmopolitismo andino contemporáneo que con seguridad puede defenderse. Si para los occidentales la reubicación de los campesinos en la ciudad es indicativa de una absoluta discontinuidad en tanto el esencialismo del modelo tradicionalista es socavado, para los andinos puede ser casi emblemático de lo que significa ser andino. No es necesario negar la patente interrupción extrema involucrada en la transición de un marco rural a uno urbano para que esto sea cierto, ya que tales interrupciones, al igual que la capacidad creativa para acomodarlas al tiempo que se mantiene la integridad propia, han sido distintivas de la sociedad andina desde la conquista. Como comenta Martin Lienhard en su sugerente artículo "De mestizajes, heterogeneidades, hibridismos y otras quimeras”, los efectos de los medios de comunicación de masas, por ejemplo, no han sido realmente más extremos que las campañas de cristianización del siglo xvi. Resulta tentador adoptar el vocabulario anti-esencialista que Paul Gilroy ha desarrollado en relación con su concepto del Atlántico Negro y la región andina. La noción de tradición de Gilroy como "la memoria viva de una cambiante 
igualdad” (198) implica un tipo de fiera coherencia cultural en ruptura que uno asocia con los Andes, y siguiendo el retrato de Gilroy del Atlántico Negro, dar fe de esa coherencia supone una crítica que sitúa al colonialismo en el centro constitutivo de la tradición racionalista occidental.

Lo que resulta particularmente digno de mención es que la lucha nacionalista que describo tiene lugar en la ciudad, o al menos se halla inspirada por el encuentro de andinos y criollos que caracteriza el terreno cultural hoy día. Lima es una mega-ciudad, o lo que Saskia Sassen (34) llama una "primate city" ("ciudad primada"), donde reside una parte desproporcionadamente grande de la población nacional, ${ }^{2}$ el lugar donde, según García Canclini, se observa la ruptura definitiva de las ideologías nacionalistas (Consumidores 31), donde lo local o lo "típico" se apropia como una referencia más de la acelerada experiencia del capitalismo tardío. Sin embargo, ya que, como Ángel Rama detallara persuasivamente en su clásico La ciudad letrada, la idea de ciudad resulta central al privilegio colonial, no es de hecho ilógico que en ella tenga lugar una renovada lucha nacionalista. Según Rama, la cultura hegemónica jugó con la idea de una ciudad ideal, lo que presuponía la forma de una rígida reproducción del orden metropolitano. Esta reproducción se logró por medio de la cultura impresa. El cuerpo de "leyes, edictos y códigos” que requería el servicio de una siempre creciente burocracia no parecía surgir de la realidad material sino que más bien parecía imponérsele. Como cuenta Rama, "la ciudad real”, por contraste, floreció en una oralidad fluida en medio de aquella rigidez, amenazando con frecuencia con minar el orden que españoles y criollos trabajaban por preservar con tanto ahínco. Como el título de Matos Mar, Desborde popular, indica, las dimensiones de la situación colonial que Rama describe apenas han cambiado, con la diferencia de que ahora los criollos parecen pelear, no sólo a la defensiva, sino una batalla pérdida.

Bajo un escrutinio más estrecho, no obstante, las afirmaciones de "lo andino” son más que ligeramente ambivalentes. Las imágenes de la ciudad con frecuencia muestran un deseo tanto de contener como de afirmar a los nuevos residentes urbanos. Cuando la emigración rural se describe como una invasión, como una avalancha que amenaza sepultar Lima, como la toma de su centro; cuando los nuevos asentamientos son descritos como enjambres y los distritos residenciales criollos como islas en medio de un mar populoso, el sentido de alarma apenas se encubre. Uno no olvida que De Soto se apresura a recordarnos que por ilegales que sean sus actividades, los andinos de la ciudad, en definitiva, no son “antisociales”.Cauto para evitar minar la sensación de seguridad que pretende ofrecer con esta rápida distinción, De Soto elige no explayarse sobre cuál puede ser la diferencia entre "ilegalidad" y lo "antisocial”.

GÉNERO

Para aquellos familiarizados con el nacionalismo del mundo andino, quizás no resulte sorprendente que su nueva versión tenga como característica el estar determinada por el género. Las dimensiones espaciales agresivamente amorfas y fluidas de las metáforas que

${ }^{2}$ Aproximadamente un tercio de la población del Perú vive en Lima. 
describen la "ciudad real" de Lima evocan el espectro del exceso femenino, y con seguridad, la definición colonial de la feminizada masa india es, hay que admitir con tristeza, todavía operativa. Aun cuando es sin duda importante distinguir -y criticar- el modo peculiar en que se experimenta la globalización en un contexto poscolonial como el Perú, dado el carácter masculino de buena parte del discurso nacionalista, uno se pregunta si tal discurso (o sólo tal discurso) es necesariamente el modelo político más productivo con que abordar las complejas fuerzas sociales de la Lima contemporánea.

El problema del género ha sido siempre un tema muy cargado de implicaciones en la región andina, solapándose con identidades raciales y étnicas. Sin embargo, y quizás por esa misma razón, el género ha sido en muchos aspectos poco investigado, permitiendo que esas identidades coloniales determinadas por él persistan ante la falta de examen, influyendo subrepticiamente en el contenido y la forma. Tomemos por ejemplo el siguiente enunciado de Matos Mar en que dice que "es importante destacar la fuerte participación femenina” en el sector informal debido a la flexibilidad horaria de las mujeres y a su habilidad para trabajar fuera de casa (61). Y por supuesto, las mujeres constituyen una gran parte de la mano de obra informal. El comentario no podría ser más irónico, no obstante, ya que a pesar del reconocimiento de que las mujeres son piezas clave y únicas de la economía informal, se trata de la única mención que de ellas se hace en todo el libro. Si se concediese al problema del género mayor legitimidad como categoría analítica, tales descuidos no tendrían lugar. Las mujeres prácticamente no aparecen en uno de los libros más influyentes producidos desde los años ochenta, Buscando un Inca. Parece que no fueran partícipes en las utopías andinas que son el tema del libro de Flores Galindo. Esta omisión es especialmente notable, ya que la rebelión de una de las figuras más celebradas en ese libro - Tupac Amaru II- fue llevada a cabo en estrecha y documentada colaboración con su esposa, Micaela Bastidas. ${ }^{3}$ En la importante obra de los críticos literarios Antonio Cornejo=Polar y Martin Lienhard, en tanto el sujeto andino se aleja del centro por las líneas de etnia y lenguaje, el género es, de nuevo, una categoría olvidada. Al respecto, quizás las elaboraciones contemporáneas del andino sí guarden (como reclaman los estudiosos conservadores en general) similitud con un indigenismo esencializador y temprano, ya que dicho indigenismo era notoriamente masculinizador cuando no completamente misógino en ciertas ocasiones.

No deseo pasar por alto el importante trabajo de muchas estudiosas contemporáneas. La historiadora Cecilia Blondet, la socióloga Delma del Valle y la antropóloga Norma Adams, para nombrar sólo a algunas, han contribuido de modo inestimable al estudio de la mujer en el sector informal. En ciertos aspectos, no obstante, estas estudiosas aún deben alterar la naturaleza de la discusión de modo crucial. Esto es: se necesita una elaboración que haga del género una categoría analítica, un modo que vaya más allá del hecho de descentrar al sujeto nacional, o lo que resulta más prometedor, un tema que exceda, aun cuando no excluya necesariamente, una perspectiva nacionalista. Al tiempo que existe una tendencia -o deseo- por parte de muchos estudiosos de celebrar un cosmopolitismo andino específicamente masculino, sus colegas femeninas se han centrado en la emigración

\footnotetext{
${ }^{3}$ Quisiera agradecer a Misha Kokotovic por llamar mi atención sobre este aspecto.
} 
como proceso de liberación de las condiciones que explotaban y oprimían a las mujeres del campo. En este escenario, la etnia, y por extensión la raza, son una carga para la mujer, y la emigración resulta el comienzo de un proceso en el cual, en palabras de un historiador, ésta se convierte en "individual” (“individuo”) o procede del "servility” (“servilismo”) a la “citizenship” (“ciudadanía”) (Blondet “Establishing...” 12; Muchas 4). La reciente investigación centrada en la mujer que trabaja en los mercados callejeros, probablemente debido al modo ambiguo en que se posiciona con respecto al género y a la política de clase, ha cuestionado las presuposiciones teleológicas que subyacen en esta narrativa sobre el camino que lleva del ámbito rural al urbano. Marisol de la Cadena, por ejemplo, explora cómo el éxito de una de estas mujeres en la arena urbana no implica necesariamente la disolución de sus lazos rurales; de hecho, esos lazos se pueden ver reforzados por tal éxito (Indigenous 182). De igual modo, el trabajo de Marcia Stephenson sobre la Bolivia andina constituye una excepción notable a la perspectiva que busca el desarrollo implícito en la historia de ese camino sin retorno hacia una mujer menos determinada por la raza. Cuando hace hincapié en cómo las esposas de los mineros bolivianos, en vez de identificarse con las políticas fuertemente basadas en el sistema de clases tradicional del sector minero, adoptan estrategias de superviviencia que se apoyan en "indigenous practices of exchange and reciprocity, drawing upon ayllu traditions of extended kinship relations" ("las prácticas indígenas de intercambio y reciprocidad, que a su vez se basan en las tradicionales relaciones de parentesco extendido del ayllu"), la autora se resiste a representar la actividad de la mujer de manera que se acomode a los modelos sociales, incluyendo los radical-progresistas que perpetúan la marginalización del indio -o mujer-que no ha sido apropiadamente domesticado (95).

En la sensación de alarma que produce la presencia femenina urbana, no obstante, funciona no sólo la ideología colonial. Esto es, la presencia urbana andina no sólo ha sido feminizada o codificada como femenina sino que, como ya mencioné, las mujeres están presentes en grandes cantidades en la mano de obra informal. Desde la década de los ochenta, cuando tantos habitantes del altiplano fueron reclutados o victimizados en la guerra entre la guerrilla de Sendero Luminoso y las fuerzas armadas gubernamentales, y cuando escatimar una vida en los Andes se hizo más difícil que nunca, las mujeres vinieron a dominar los patrones de la emigración cada vez más. Resulta típico que las mujeres que han emigrado a Lima en las dos últimas décadas tengan mucha menos educación, muchas menos destrezas con que comerciar y menos recursos en general que aquellos andinos que decidieron emigrar en el pasado. Estos factores han conformado profundamente la naturaleza del cosmopolitismo andino, aunque no necesariamente de modo predecible. En particular, durante los años de crisis en los ochenta y principios de los noventa, cuando la pobreza y la inestabilidad política alcanzaron proporciones endémicas, la mujer se hallaba entre las figuras más politizadas del sector informal de Lima, precisamente por su participación en actividades asociadas a una esfera privatizada. En su participación en el programa del "vaso de leche”, en las “ollas comunitarias” y "los comedores populares”, se puede constatar cómo lo privado se hace público. Los esfuerzos de las mujeres son colectivos en este caso y en su llamado a apoyar estos programas por medio de protestas públicas, las tareas asociadas con el papel materno se vuelven un pretexto para un sujeto femenino también más público. 
Hay en juego, sin embargo, más de una versión de la maternidad en el Perú contemporáneo. Como informara la periodista Alma Guillermoprieto, cuando Mario Vargas Llosa perdió las elecciones ante Alberto Fujimori en 1990, "hysterical upper class women outside his campaign headquarters shouted for a coup” ("mujeres de clase alta, histéricas, gritaban en el exterior del cuartel general de su campaña pidiendo un golpe de Estado”, 83). Por histérica que fuese su llamada a un golpe, la mujer peruana criolla "showed an understanding of what an unreconstructed upper class needs in order to stay in power" ("mostraba su comprensión de lo que, a falta de ser reconstruida, la clase alta necesita para mantenerse en el poder”). Estas mujeres consternadas por la derrota de Vargas Llosa habían asistido con anterioridad a un discurso que muchos consideraban el inicio no oficial de su campaña en la Plaza San Martín. Alquilaron suites en el Hotel Bolívar para poder escuchar con comodidad por encima de la plaza donde hubieran tenido que "rub shoulders with the cholos" ("rozarse con los cholos", 77). Como esta frase de Guillermoprieto sugiere, la escena participa de una moral de higiene distintiva, donde las identidades de género y raza se desenvuelven en una dinámica de contagio y contención.

La prevención del género como categoría analítica en el discurso andino es una de tales estrategias de contención, uno de los métodos por los que un interrogatorio -y una reelaboración- de la relación profundamente conflictiva entre género, raza, etnia y clase es puesta en cuarentena. Es cierto que se ha hecho un progreso notable en el campo de la antropología y podemos pensar en el trabajo de Marisol de la Cadena, Florence Babb, Mary Weismantel o Billie Jean Isbell. Aun cuando hay por supuesto excepciones, la reticencia (por inconsciente que sea) a tratar el género de manera seria parece particularmente pronunciada en el campo de la literatura. Esto es verdad al nivel más básico y empírico. Como escritora y crítica, Marjorie Agosin hace notar que, cuando se compara con otras regiones de América Latina, las escritoras de los Andes apenas si poseen reconocimiento internacional (o siquiera nacional). Sencillamente, sus nombres no circulan. Al recordar el análisis de Ángel Rama entre el orden metropolitano y la “ciudad real”, femenina u oral, no podemos evitar especular que quizás esta reticencia por parte del cuerpo literario tenga algo que ver con la condición de élite asegurada a la cultura letrada a lo largo de la historia colonial andina. ${ }^{4}$ Es en este sentido que debemos incluir el Texto en la relación metonímica entre entre Género, Raza, Etnia y Clase que caracteriza la sociedad andina poscolonial. La literatura como institución parece estar especialmente asociada con una élite colonial distintivamente masculina. Se nos recuerda el papel siempre contradictorio de la literatura, donde, paradójicamente, proyectos nacionalistas se llevan a cabo por medio de lo que en Latinoamérica resulta ser una práctica de la élite. Aun así, cuando la mujer, y de modo más amplio el problema del género, son incluidos como un factor más de la ecuación, el proyecto nacionalista no resulta únicamente contradictorio sino que, como demuestran nuestras metáforas de la alarma, se pone totalmente en peligro.

Aun así, más allá del entramado de ilusiones nacionalistas, el asunto del género puede contribuir de un modo más acorde a un tipo de visión social que concuerde más con las

\footnotetext{
${ }^{4}$ En un seminario sobre "Mujeres en las Américas” en Cornell University, el semestre de primavera del 2001, la noción de que la condición de élite de la literatura en los Andes era responsable de la resistencia a ocuparse del problema del género me fue sugerida por Billie Jean Isbell.
} 
identidades variadas, flexibles y altamente intercambiables que constituyen el moderno Perú. En palabras de Marisol de la Cadena: "peasant women... are the most 'Indian' of all” (“las mujeres campesinas... son las más indígenas de todas”, “Women” 338). Son las más pobres y, como dice de la Cadena y diría también la opinión general, son los más "locales” de los sujetos. ¿Qué significa ser “local” en una metrópoli de cerca de siete millones de personas? ¿Y cuál es la relación entre las llamadas prácticas "locales” y las políticas neoliberales que han sido aplicadas en el Perú por más de una década y que son aceptadas por muchos, como en gran parte de América Latina, como enunciados posideológicos? La creciente dificultad de imaginar una alternativa al neoliberalismo apoya la convicción de muchos intelectuales progresistas sobre el carácter "neocolonial” de la globalización. Destacar el problema del género no sólo hace resaltar los sujetos que a menudo son excluidos de las ideologías nacionalistas, sino que también, dada la resonancia que con persistencia local poseen las identidades femeninas, hace resaltar el modo concreto en que el flujo de capital, gente e información que ha llegado a definir nuestra era, opera en una ciudad del Tercer Mundo como es Lima. Un acercamiento a semejante ciudad determinado por el género requiere que pensemos el cosmopolitismo por medio de lo local.

Finalmente, ¿qué hay de los otros cosmopolitismos, de aquellos que tradicionalmente han sido asociados con dicho término? Las élites peruanas son más cosmopolitas que nunca, encontrándose en casa tanto en Lima como en París, Nueva York, Londres y Madrid. Esto es particularmente cierto para ciertos miembros bien conocidos de la comunidad intelectual. Novelistas como Mario Vargas Llosa y Alfredo Bryce Echenique han decidido residir en Europa, mientras que el escritor Jaime Bayly pasa más tiempo en Miami que en Lima. Intelectuales como ellos son los que el antropólogo Ulf Hannerz tiene en mente cuando se refiere a las experiencias que él cree son consecuencia de un mundo más continuo. Hannerz escribe acerca de la "interplay of mastery and surrender" (“interacción entre dominación y sometimiento”, 240) incluida en el proceso de obtener competencia en otra cultura, una práctica que ha venido a ser especialmente destacada en la era transnacional. Estas interacciones con matices corresponden a la producción de un nuevo tipo de subjetividad: "the self is constructed in the space where cultures mirror one another” (“el yo es construido en el espacio donde las culturas se reflejan la una a la otra”). Uno podría argumentar, sin embargo, que la competencia bi o multicultural ha sido por mucho tiempo del dominio particular, e incluso una obligación, de la colonia subalterna. Saber el cómo, el cuándo y el dónde operaba la adoración cristiana, en oposición al concepto de la costumbre autóctona, por ejemplo, fue para la población indígena un problema de supervivencia.

Aun así, para Hannerz hay una limitación importante, la cual distingue a la élite de los inmigrantes que han construido la economía informal de Lima. "The cosmopolitan" escribe, "may embrace the alien culture, but he does not become committed to it" ("El cosmopolita puede abrazar la cultura foránea, pero no se compromete con ella. En todo momento sabe dónde se encuentra la salida”). Saber donde se encuentra la salida no es un privilegio que posea la mayoría de andinos con recursos severamente limitados.

Pero, ¿no reconforta Hannerz al cosmopolita de la élite con argumentos que no suenan a verdaderos en el “mundo continuo” de hoy? Este punto lo dramatiza intensamente 
el crítico literario Antonio Cornejo Polar en un ensayo que retrata un encuentro contemporáneo de cultura oral y escrita. Cornejo Polar , con referencia a una descripción de Mario Vargas Llosa de la Biblioteca Nacional de Lima, se refiere a los vastos mercados andinos que rodean a la Biblioteca Nacional y que han transformado dramáticamente el que fuera aristocrático y colonial centro de Lima. Uno sigue al intelectual asediado que, desorientado al dejar la biblioteca, se encuentra perdido en lo que otro crítico refiere como el "populoso mar" andino. La imagen de Cornejo Polar encuentra recursos en el cuento de Jaime Bayly mencionado con anterioridad, donde el narrador comenta que para las clases altas Lima ha sido reducida a escasas cuadras. El privilegio es, en este caso, una virtud precaria, particularmente el privilegio perteneciente a la cultura de la clase alta, donde el concepto de "hogar" se ha vuelto irreconocible casi de la noche a la mañana, y donde la propia salida no puede reducirse a un simple concepto de elección. Podría argumentarse que el mensaje representado por el ejemplo de Cornejo Polar se aplica solamente a la élite colonial, pero dadas las transformaciones demográficas, donde las comunidades de la diáspora hacen que su presencia se sienta cada vez con mayor intensidad en las capitales metropolitanas, haciendo de este modo más difusa la separación entre centro y periferia, la diferencia es más bien de grado.

Es crucial pensar las dos caras de la globalización al mismo tiempo: donde una alarmante estandarización de la cultura se une paradójicamente con un sentido de la producción del conocimiento distintivamente local; donde la ingenuidad que la pobreza hace necesaria se enfrenta con la cultura, la cual coincide con una hasta ahora inimaginable proliferación de riqueza; donde la política de desarraigo y diáspora, irónicamente, fuerza a la élite a conocerse de un nuevo modo, y que (esperamos) consecuentemente hará añicos la complacencia cultural y política que ha hecho a la ciudad del Tercer Mundo tan invisible para tan poderosa minoría.

Bibliografía

Agosin, Marjorie. “Foreward”. Fire from the Andes: Short Fiction by Women from Bolivia, Ecuador, and Peru. Albuquerque: University of New Mexico Press, 1998. xi-xvi.

Bayly, Jaime. “Extrañando a Diego”. McOndo. Alberto Fuguet y Edmundo Paz Soldán, eds. Barcelona: Grijalbo-Mondadori, 1996.

Blondet, Cecilia. Muchas vidas construyendo una identidad: las mujeres pobladoras de un barrio limeño. Lima: Instituto de Estudios Peruanos, 1986.

"Establishing an Identity: Women Settlers in a Poor Lime Neighborhood". Women and Social Change in Latin America. Elizabeth Jelin, ed. London: Zed Books Ltd, 1990. 12-46.

Bueno, Raúl. “Heterogeneidad migrante y crisis del modelo radial de cultura”. Indigenismo hacia el fin del milenio: homenaje a Antonio Cornejo-Polar. Mabel Moraña, ed. Pittsburgh: IILI, 1998. 253-68.

Burt, Jo-Marie \& César Espejo. “The Struggles of a Self-Built Community”. NACLA: Report on the Americas 28/4 (Jan-Feb 1995): 19-25. 
Cadena, Marisol de la. Indigenous Mestizos: The Politics of Race and Culture in Cuzco, Peru, 1919-1991. Durham: Duke University Press, 2000.

“'Women are More Indian': Ethnicity and Gender in a Community Near Cuzco”. Ethnicity, Markets, and Migration in the Andes: At the Crossroads of History and Anthropology. Brooke Larson \& Olivia Harris, eds. Durham: Duke University Press, 1995.

Calderón, Fernando. "Identidad y tiempos mixtos o cómo pensar la modernidad sin dejar de ser boliviano”. Imágenes desconocidas: la modernidad en la encrucijada postmoderna. Fernando Calderón, ed. Buenos Aires: CLACSO, 1988. 225-29.

Cornejo Polar, Antonio. "Una heterogeneidad no dialéctica”. Revista Iberoamericana LXII/176-177 (Julio-Diciembre 1996): 837-44.

Flores Galindo, Alberto. Buscando un Inca. Lima: Horizonte, 1986.

“El rescate de la tradición”. Márgenes: Encuentro y debate 8 (1991): 7-19.

García Canclini, Néstor. Consumidores y ciudadanos: conflictos multiculturales de la globalización. México: Grijalbo, 1995.

Culturas híbridas: estrategias para entrar y salir de la modernidad. México: Grijalbo, 1990.

Guillermoprieto, Alma. The Heart that Bleeds: Latina America Now. New York: Vintage Books, 1994. 68-91.

Gilroy, Paul. The Black Atlantic: Modernity and Double Consciuosness. Cambridge: Harvard University Press, 1993.

Hannerz, Ulf. “Cosmopolitans and Locals in World Culture”. GlobalCulture: Nationalism, Globalization and Modernity. Mike Featherston, ed. London: Sage Publications, 1990.

Jameson, Fredric. "Notes on Globalization as a Philosophical Issue”. The Cultures of Globalization. Fredric Jameson and Masao Miyoshi, eds. Durham: Duke University Press, 1998.

Lazarus, Neil. Nationalism and Cultural Practice in the Postcolonial World. Cambridge: Cambridge University Press, 1999.

Lienhard, Martin. La voz y su huella: escritura y conflicto étnico-social en América Latina (1492-1988). La Habana: Casa de las Américas, 1990.

"De mestizajes, heterogeneidades, hibridismos y otras quimeras”. Asedios a la heterogeneidad cultural: libro de homenaje a Antonio Cornejo-Polar. José Antonio Mazzotti y U. Juan Zavallos Aguilar, eds. Philadelphia: Asociación Internacional de Peruanistas, 1996. 57-80.

Matos, Sylvia. “Una década de cultura andina”. Ciudad y cultura 9/27 (Mayo 1991): 8693.

Matos Mar, José. Desborde popular y crisis del estado: el nuevo rostro del Perú en la década de 1980. 7 ed. Lima: CONCYTEC, 1988.

Nugent, José Guillermo. El laberinto de la choledad. Lima: Fundación Friedrich Ebert, 1992.

Pratt, Mary Louise. Imperial Eyes: Travel Writing and Transculturation. London and New York: Routledge, 1992. 
Rama, Ángel. La ciudad letrada. Hanover: Ediciones del Norte, 1984.

Rowe, William \& Vivian Schelling. Memory and Modernity: Popular Culture in Latin America. London: Verso, 1991.

Sassen, Saskia. Cities in a World Economy. London: Pine Forge Press, 2000.

Soto, Hernando de. El otro sendero: la revolución informal. Lima: El Barranco, 1986.

Stephenson, Marcia. Gender and Modernity in Andean Bolivia. Austin: University of Texas Press, 1999.

Vargas Llosa, Mario. Historia de Mayta. Barcelona: Seix Barral, 1984. 